Salime Hadad 1

\title{
Preventable infant mortality and quality of health care: maternal perception of the child's illness and treatment
}

\author{
Mortes infantis por causas evitáveis \\ e qualidade dos serviços de saúde: \\ um estudo da percepção materna da doença \\ e do atendimento à criança doente
}

Elisabeth França 2

Elizabeth Uchôa 3,4

\footnotetext{
1 Distrito Sanitário Leste Secretaria Municipal de Saúde de Belo Horizonte. Rua Bicas 58, Belo Horizonte, MG 31030-160, Brasil. salime@pbh.gov.br 2 Departamento de Medicina Preventiva e Social, Faculdade de Medicina, Universidade Federal de Minas Gerais. Av. Alfredo Balena 190, Belo Horizonte, $M G$ 30130-100, Brasil. efranca@medicina.ufmg.br 3 Centro de Pesquisas René Rachou, Fundação Oswaldo Cruz. Av. Augusto de Lima 1715, Belo Horizonte, $M G$ 30190-002, Brasil. uchoae@cpqrr.fiocruz.br 4 Departamento de Psiquiatria e Neurologia Faculdade de Medicina, Universidade Federal de Minas Gerais. Av. Alfredo Balena 190, Belo Horizonte, $M G$ 30130-100, Brasil.
}

\begin{abstract}
This study used a qualitative methodology to analyze the discourse of mothers from Greater Metropolitan Belo Horizonte, Minas Gerais, Brazil, whose infant children had died from what were considered avoidable causes (diarrhea, malnutrition, and pneumonia), seeking to elucidate the factors associated with utilization of health care services. Identification of the illness by the mother was related to perception of specific alterations in the child's state of health. Analysis of the alterations helped identify the principal characteristics ascribed to each alteration and their relationship to the search for treatment. The authors also studied the mother's assessment of treatment received at health care facilities; $43.0 \%$ of the cases involved problems related to the structure of health care services or the attending health care professionals. In $46.0 \%$ of the cases, mothers associated the child's death with flaws in the health care service. The study group showed a variety of interpretations of illness, often distinct from the corresponding biomedical concepts. The fact that attending health care personnel overlooked or underrated the mother's perception of the illness and the lack of communications between health care personnel and the child's family had an influence on the child's evolution and subsequent death.
\end{abstract}

Key words Postneonatal Mortality; Medical Care; Health Care Quality

Resumo Neste trabalho foi analisado, através de metodologia qualitativa, o discurso de mães moradoras da Região Metropolitana de Belo Horizonte que perderam seus filhos por causas consideradas evitáveis (diarréia, desnutrição e pneumonia), buscando investigar os fatores associados à utilização dos serviços de saúde. Foi observado que a identificação da doença pela mãe está relacionada à percepção de alterações específicas no estado de saúde da criança. A análise de cada alteração permitiu conhecer as principais características atribuídas a cada uma e sua relação com a procura de tratamento. Também foi estudada a avaliação das mães sobre o atendimento recebido nos serviços de saúde, sendo informado em 43,0\% dos casos, problemas relacionados à estrutura dos serviços de saúde e ao profissional do serviço de saúde. Em 46,0\% dos casos, as mães relacionaram a causa da morte da criança com as falhas do serviço de saúde. Há no grupo estudado um variado conjunto de interpretações de doenças distinto, muitas vezes, dos conceitos biomédicos. O desconhecimento elou desvalorização da percepção materna da doença, com ausência de comunicação dos profissionais de saúde com a família da criança doente tiveram influência sobre o óbito.

Palavras-chave Mortalidade Pós-Neonatal; Cuidados Médicos; Qualidade da Assistência à Saúde 


\section{Introduction}

Recent anthropological studies have focused on health care users' perceptions of the quality of health services, based on the belief that this perception directly influences the search for and choice of treatment, which are based mainly on prior experience. The majority of such studies highlight the importance of the following factors: waiting time, cost and form of payment, treatment received from health care staff, cleanliness of the facility, level of communication between health care staff and patients, access to health services, understanding of personal problems, reliability of institutions, technical competence, continuity of treatment by the attending physician, and others (Gattinara et al., 1995). However, Atkinson (1993) calls attention to the importance of including an analysis of quality of services within a broader context that encompasses socioeconomic conditions, cultural differences, and models for interpretation of illness by the population.

The influence of the social and cultural universe on the adoption of risk behaviors and utilization of health care services has been demonstrated by various studies (Uchôa \& Vidal, 1994). Eating habits, child care patterns, religious practices, traditional medical treatment, and other factors have been considered critical in the natural history of many infectious diseases. Various societies have different labels for similar illnesses, and the high prevalence of a given disease is not sufficient for it to be considered as such by specific populations (Eisenberg, 1981). It is a given community's perception of a specific alteration that indicates the problem's severity and determines both the decision to treat and the appropriate form of treatment. Each community constructs its own universe of health problems, and there is a relationship between the way it perceives health problems and the way it proceeds to solve them (Corin et al., 1992, 1993; Uchôa et al., 1993).

According to Kleinman (1978), the illness process begins with the awareness of a change in bodily sensations and proceeds to classification of the suffering by the individuals themselves or by their families. According to this view, personal or family action focuses on the search for recovery, and advice is sought from other family or community members and from formal or "informal" health professionals (the latter including curers, prayer healers, etc.). This sequence is rarely described in the legitimate health system's records. The concept of "explanatory model” proposed by Kleinman (1980) aims precisely to investigate and systematize the cognitive schemata employed by different categories of individuals to deal with health problems. This same author (Kleinman, 1980) distinguishes between the set of beliefs, behavioral norms, and expectations underlying the professional explanatory model and that underlying the explanatory models employed by ailing individuals and their families. Based on the distinction between "disease" and "illness", Kleinman (1978) contends that "illness" refers to the symptoms and incapacity perceived by the patient, family, and social network and that "disease" is a translation of the problem in technical biomedical terms. According to this perspective, medicine diagnoses and treats diseases (abnormalities in the structure and functioning of body organs and systems), while patients may be suffering from an illness, experiencing changes in their state of well-being and social functioning, that is, a human experience of the disease as illness.

Choice of treatment, according to Nations \& Rebhun (1988), is based not only on logical considerations of symptoms and methods, but is also affected by such factors as location, language, economic issues, access to transportation, and ideological issues like beliefs and cultural values, social status, expectations, and social norms. In a study performed in the State of Ceará, Brazil, these same authors observed that families displayed an eclectic health care-seeking pattern, consulting various types of healers, sometimes sequentially, other times concomitantly, often resulting in mixed messages, discontinuity in care, maternal exhaustion, and occasionally the child's death. Families made efforts to search beyond the resources of their small community with the objective of saving their children's lives. For the more impoverished groups, finding a physician involved seeking access to a complex technology, including a hospital, radiology, surgeries, and intravenous rehydration. Mothers described long treks and long waits to consult one doctor after another, carrying a child that was yelling, vomiting, or defecating over long distances.

In another study conducted in Karachi, Pakistan, Mull et al. (1994) observed that the visit to the hospital was described as a tiresome journey involving long waits; mothers reported having to find someone to accompany them, to do their housework, and to care for the other children who stayed behind at home. Some mothers reported delaying the trip to the hospital out of fear that the child would be hospitalized, or in this case because they would be forced to stay away from home for days.

In Greater Metropolitan Belo Horizonte $(\mathrm{GMBH})$ in the State of Minas Gerais, Brazil, 
a study performed in 1991-1992 showed that mothers of children who had died from preventable causes (like diarrhea, malnutrition, and pneumonia) had visited an average of three health care services during the course of the child's disease (França, 1995). Such diseases, considered preventable, could have been treated effectively if they had been diagnosed early and adequately and timely treatment had been instituted (Lansky \& Mendonça, 1996). Note that the proximity and technological capability of the health care services were insufficient to save the lives of these children. To investigate the universe of representations and behaviors in these mothers, a discourse analysis was subsequently performed, seeking to identify the parameters they used to identify the child's illness (Kleinman, 1978) and how this influenced their search for treatment. The study also sought to unveil the factors associated with utilization of health care services, to understand the mothers' perceptions of the care received from the services, and to investigate the repercussions of this perception on the conduct adopted subsequently during the child's illness.

\section{Methodology}

\section{Study area}

GMBH is located in the State of Minas Gerais, southeast Brazil, with a population of 3,358,633 according to the 1991 Brazilian Census (IBGE, 1993), with some $2 \%$ of children under one year of age. In 1992 there were 1,032 post-neonatal deaths in GMBH, of which 589 (57\%) reported diarrhea, pneumonia, or malnutrition as the underlying cause of death, corresponding to $29.1 \%$ of total infant mortality (França, 1995).

Cases were selected according to biomedical criteria following hospital investigation into the underlying cause of death to study the determinants of infant mortality (França, 1995). All post-neonatal deaths in GMBH were analyzed for the period from May 1991 to April 1992 in which the underlying cause of death was diarrhea, pneumonia, or malnutrition.

\section{Data collection and analysis}

This study focused on data collected from household interviews. Some 395 household interviews were selected, with mothers of cases (children who had died of diarrhea, pneumonia, or malnutrition). Data were collected through a questionnaire with four open questions (reports). Answers were sub-divided into four sec- tions pertaining to the topics discussed in each question: (a) onset and development of the illness; (b) changes brought about by the illness for the mother and family; (c) changes brought about by the death for the mother and family; and (d) causes of the child's death.

Analysis of the open questions was based on the analytical model for systems of signs, meanings, and actions (Corin et al., 1992, 1993; Uchôa et al., 1993) which aims precisely at systematic knowledge of the ways of thinking and acting among specific populations. This model allows for knowledge of the conceptual logic that organizes the field of cultural representations associated by a given population with a given illness and the contextual elements (personal experience, cultural habits, environmental factors, etc.) which can influence the translation of these representations into concrete behaviors vis-à-vis existing health resources. The analytical model of systems of signs, meanings, and actions proposes two levels of analysis. The first level aims to systematically investigate the different elements associated with the identification of a given problem, its severity, and the need for treatment, in addition to the prime explanations vis-à-vis these problems and the reactions and actions they trigger. A second level of analysis examines the links between the "systems of signs, meanings, and actions", evaluating the specific impact of different contextual elements on the construction and evolution of reactions and behaviors (Uchôa \& Vidal, 1994). In order to operationalize the model, all the reports were initially read in uniform fashion, separating them by sections of questions, with the objective of obtaining an overall view of each case. In the second stage, the reports were read according to the sections of questions, and notes were made on relevant facts for the study matter. This careful reading of the set of reports helped identify recurrent themes. Next, these themes were sub-divided and transformed into categories, distinguishing between two hierarchical levels: (1) broader, more general categories defined as content records; (2) more finetuned sub-categories defined as content categories. The final list included 292 content categories (fine categories) grouped into 68 content records (broader categories) that were aggregated into 13 major groups. Each content category received a two or three-letter code to facilitate marking it in the text. All of the reports were then classified and coded manually to prepare them for keying-in (marking the coding in the digital text). This phase used the Qualittat software (Demicheli \& Uchôa, 1997) to index each excerpt referring to one or more content cate- 
gories with the corresponding codes, allowing for the calculation of frequencies of each content category in the reports as a whole, selection of a given category with a hard copy of the corresponding specific excerpts, and cross-analysis between selected categories. From there on the analysis aimed at reconstructing the links between perceptions, interpretations, reactions, and treatment decisions.

\section{Results}

\section{Maternal perception of the child's illness}

Analysis of maternal discourse on the onset and evolution of the child's illness showed that identification of the illness was related to perception of some specific changes in the child's state of health, referred to here as signs. Some 55 different types of signs were identified in the reports. Some were particularly valued by mothers as indicators of the onset or evolution of the illness, like diarrhea, vomiting, fever, fatigue, cough, crying, lack of appetite, colds, grunting, weight loss (literally "thinning”), and full chest (Table 1).

The three most frequent signs (diarrhea, vomiting, and fever) in the mothers' reports were mainly associated with onset of the illness, according to the mothers themselves. Diarrhea was described according to the color (greenish)

Table 1

Most frequent signs 1 in maternal discourse concerning the onset and evolution of child's illness. Greater Metropolitan Belo Horizonte, Minas Gerais State, Brazil, 1991-1992.

\begin{tabular}{lcc}
\hline \multirow{2}{*}{ Signs } & \multicolumn{2}{c}{ Reports 2} \\
& $n$ & $\%$ \\
\hline Diarrhea & 164 & 41.5 \\
Vomiting & 157 & 39.7 \\
Fever & 126 & 31.8 \\
Fatigue & 94 & 23.8 \\
Cough & 89 & 22.5 \\
Crying & 80 & 20.2 \\
Lack of appetite & 71 & 18.0 \\
Cold & 62 & 15.6 \\
Grunting & 48 & 12.1 \\
Weight loss ("thinning") & 39 & 9.9 \\
Full chest & 38 & 9.6 \\
\hline
\end{tabular}

1 The same report could include several signs. 2 The percentage was calculated based on the 395 reports analyzed in the study. and consistency of stools, increased frequency of bowel movements, and the appearance of blood or phlegm. According to some mothers, the diarrhea had been contracted through contact with the health service, whether during hospitalization, vaccination, or use of physician-prescribed medication: “...he was in the hospital and got out on November 14, came back but was coughing and wheezing, and the doctor prescribed an antibiotic, which I bought, and he began to have diarrhea, so I stopped the antibiotic and gave him [oral rehydration] solution...". Some mothers also identified teething as a cause of the diarrhea. This association was also found in some studies conducted on populations in northeast Brazil (Nations \& Rebhun, 1988; Scheper-Hughes, 1984). Another cause of diarrhea identified by some mothers was "espinhela caída" (literally "drooping chestbone") a folk illness identified by various Brazilian population groups. Some mothers described vomiting as an alteration that could weaken the child. In cases where vomiting was associated with worsening of the illness, mothers mentioned that the vomit had a yellowish color or contained phlegm or blood. Fever was mainly recognized by the child's reddish skin color and warm forehead; fever's main characteristics were intensity, persistence, and intermittence ("comes and goes").

Colds, cough, full chest, and fatigue constitute the group of alterations mothers associated most frequently with respiratory problems. Colds were mainly associated with the onset of the illness. A cold was sometimes identified as having appeared soon after birth, suggesting that some mothers believed it had been transmitted during pregnancy, “...the child already came home from the hospital with a cold, and the mother said that before giving birth she was having a bad cold..". In a study conducted in the State of Pernambuco, northeast Brazil, Scheper-Hughes (1984) identified a belief that the mother's weakness could be transmitted to the child in utero. In the current study, allergies and the child's exposure to the hospital environment were also identified as causes of colds.

Cough was also identified as a frequent alteration during onset of the illness and was associated with weather conditions and exposure to the hospital environment. The cough's intensity and tone (dry or hoarse) were described as its main characteristics; a cough's persistence, increased frequency, and nocturnal pattern were associated with severity of the illness.

Fatigue was generally described by mothers as the child's difficulty in breathing, and the expressions used in the reports were: "difficulty 
breathing”, "short of air", “deep breathing”, "can't breathe”, “out of breath", “stops breathing”, and "fatigued". Interestingly, sometimes there was a rather precise description of the moment in which the change first appeared: “...on June 20th, 1991, at 9:30 PM, after the baby nursed, she got very tired...". This may be explained by the fact that mothers frequently associate this alteration with a worsening of the illness. In a study in Pakistan, Mull et al. (1994) observed that mothers clearly perceived the presence of two important symptoms, rapid breathing and chest retractions. The report of fatigue by mothers in the current study is apparently similar to what is described as rapid breathing in Pakistan.

Mothers frequently associated another group of alterations with the child's eating patterns, including lack of appetite and weight loss (or literally "thinning"). Mothers described lack of appetite as a decrease in food intake which could weaken the child. Weight loss was referred to in various ways. Some mothers reported that although they had observed the child's gradual thinning, they did not believe that the child was ill, or that it was a serious illness: “...he was getting very thin (since around May 15th), but I didn't realize he was ill...". Some mothers explicitly associated weight loss with the child's refusing food, others associated it with the child's hospitalization. In some cases, lack of appetite was identified as the cause of the child's weight loss during hospitalization, while in other cases the mothers reported that the child had gone hungry in the hospital and that this had been the cause of death, “...I think the hospital let her die of hunger. Because I would give her the baby bottle and she wanted to eat. Looks like the hospital was out of food...." The occurrence of weight loss and lack of appetite during hospitalization was viewed as an indicator of worsening of the illness.

According to Nations \& Rebhun (1988), “malnutrition" is a biomedical concept unknown to mothers, who prefer to use the term "weakness" to define it. The literature shows an association between "weakness" and death in children (Nations \& Rebhun, 1988; Scheper-Hughes, 1984). In the current study mothers used the term "weakness" both to refer to the child's physical constitution and its nutritional status. Thus, the child could either be born weak or become weak. In the former case, it was the child's nature, as something predetermined; in the latter, the illness was weakening the child, removing its appetite. However, unlike the studies cited above, some mothers also used the term "malnutrition" to refer to the child's cause of death, perhaps due to contact with the attending physi- cian or other health professional during the illness or after the child's death.

Two other important alterations that mothers frequently associate with a worsening of the child's illness are grunting and crying. Grunting and crying were defined as ways of expressing needs and pain, “...he wouldn't take his bottle, and he was crying weakly and seemed to be in a lot of pain...". The mother herself defines the "type" of crying and/or grunting and interprets the child's request. Mothers frequently associated crying with severity of the illness.

\section{Illness and the search for treatment}

Analysis of the relationship between signs and the decision to take the child for treatment showed that home treatment was used in $21.9 \%$ of the cases with diarrhea, $15.2 \%$ of cases with vomiting, and $23.8 \%$ of cases with fever. It is possible that when mothers perceived one of these signs, they initially attempted to solve the problem using home remedies, probably since they did not associate them with a severe illness. Mothers appear to have considered $d i$ arrhea a common, non-serious problem, requiring simple solutions. Nations \& Rebhun (1988) observed in Ceará that not all cases of diarrhea were perceived by the study population as abnormal or requiring treatment. It is understandable in social groups lacking basic sanitation and safe drinking water that bouts of diarrhea in children are relatively frequent and constitute ordinary events.

When crying was the only alteration observed by mothers, they turned to health care services and preferably the hospital. This behavior can be explained by the association in the reports between the child's crying and severity of the illness.

In cases involving reports of colds, mothers mainly used home treatment $(31.6 \%)$ or the health posts $(31.6 \%)$. Going to the hospital for treatment may only have occurred when other alterations appeared, such as cough or fatigue. A similar fact may be observed in cases involving reports of a full chest; in such cases, mothers also turned mainly to the health post for treatment, and it was not until fatigue or cough appeared that they took their children to the hospital.

Although rarely associated with worsening of the illness, the presence of cough frequently led mothers to seek treatment in health care services, especially hospitals. In some reports, mothers observed that various health care professionals had already considered the child's cough an unimportant alteration. Such under- 
rating of the severity of this alteration by health care professionals may have induced some mothers to postpone seeking medical help again; in other words, they would only return to a health care service for treatment when alterations appeared that might be considered important by the attending health care personnel. Fatigue motivated seeking hospital care in $70.2 \%$ of cases. However, approximately $26.5 \%$ of the cases also involved a reported fever and $22.3 \%$ a reported cough.

There appears to be a logical chain of these signs, impacting the mother's behavior. Colds, cough, and in some cases full chest appear to have been the first alterations in the illness identified by mothers. They initially treated their children at home, with home remedies and self-prescribed medicines, and when the cough appeared they felt motivated to seek a health service. Underrating the importance ascribed to cough by health professionals provides a clue as to why some mothers postpone taking the children to a health service for so long and end up taking them when they are already in serious condition. Their previous experience may have taught them that the health system only receives severe cases.

Choosing the place for treatment is definitely permeated with the mothers' prior experience with health care services. Interestingly, the health post was used principally in cases in which signs associated with the onset of the disease predominated. It is possible that mothers believe that the health post is a service with simpler solutions, for less complex cases. On the other hand, the alterations most frequently associated with worsening of the illness (fatigue, grunting, crying, and weight loss) led mothers to turn directly to the hospital (over $66 \%$ of cases). When they perceive the problem's severity, mothers probably turn to what they consider the best-equipped service for solving more complex cases, that is, the hospital.

\section{Treatment received at health care services}

In $91 \%$ of the cases, mothers reported having gone to the hospital at least once $(n=359)$ over the course of the child's illness. The health post was the second most frequently used service ( $\mathrm{n}=132$ ). Mothers mentioned having made several trips to the health care services, and in the same report they may refer to treatment received at various hospitals or in different health posts.

The hospital was visited 865 times, with a mean of 2.4 visits per case (including only the 359 cases that visited the hospital). Out of the to- tal number of visits to the hospital, $13.9 \%$ were evaluated by mothers as positive, resulting in an improvement in the child's state of health, while $17.7 \%$ were considered negative (no change or worsening in the child's condition) (Table 2). In $37.7 \%$ of the cases in which mothers assessed the hospital care as negative, they associated this with medication prescribed by the physician: "...I took my child back to the hospital on March 28, the doctor prescribed some medicine, and I came back home, but it didn't do any good and I rushed him back to the hospital..." In $33.1 \%$ of the cases the negative result was attributed to the hospitalization in general, and the mothers emphasized that the child did not improve and sometimes even got worse after the hospitalization: “...he was admitted on March 27, 1991, was released in even worse shape, and came home with diarrhea...".

The health post was visited 175 times, with a mean of 1.3 visits per case (referring only to the 132 cases taken to the health post). Some $12.0 \%$ of the visits were evaluated as positive (the child improved) and $31.4 \%$ as negative (did not change or got worse with treatment) (Table 2). Some $89 \%$ of the cases assessed as negative were associated by the mothers with the medication prescribed by the health service: “...I took my child to the health post on October 3 , they gave him injections for seven days and he took them, and after five days he got worse...".

The decision to seek treatment at a different health service from the one initially visited was very frequent, and there were few cases in which mothers returned to the same health service visited before. In relation to visits for hospital treatment $(n=359)$, only $32.5 \%$ of the cases $(n=115)$ returned to the same hospital visited previously. For health posts $(n=132)$, only $17.4 \%$ of the cases $(n=23)$ returned. This low return to health posts was probably due to the fact that mothers took their children to another type of health care service, principally the hospital.

In $43.0 \%$ of cases $(n=170)$, mothers reported various problems with the health care services, divided into two major groups: (a) structural problems in the health care service and (b) problems with the attending health care professionals.

Mothers reported structural and organizational problems in health care services in $26.6 \%$ of cases: "lack of an ICU, lack of equipment... there was no ICU anywhere, the doctors even had an air pump [Ambu bag], and they were pumping the air by hand, but it didn't do any good...". Such problems were grouped into 14 sub-groups: nosocomial diseases, lack of va- 
cancies for hospital admittance, delay in care, lack of hygiene on the ward, lack of physicians, lack of continuity in treatment, absent or broken equipment, lack of information provided to parents, health workers on strike, lack of vacancies for appointment with physician, lack of medicines, lack of food, lack of vacancies in the Intensive Care Unit (ICU), and other less frequently cited problems.

In $25.3 \%$ of cases $(n=100)$, mothers identified problems in the relationship with the health care professional, “... [my child] was home for about ten days, and he got worse again and I took him back to the hospital and the doctor said it was nothing, that it was just an eating thing, and he got worse the next day and I took him back to the hospital again and he was admitted to the ICU..." These problems were organized in nine sub-groups: mistreatment, medication prescribed by health care professional aggravated the patient's condition, health care professional failed to perceive the severity of the disease, health care professional failed to prescribe medication, procedure (or intervention) performed by health care professional aggravated the disease, health care professional refused to see the child, treatment was conditioned on advance payment, health care professional failed to attempt to secure a vacancy in the ICU, among other problems.

In $46.0 \%$ of cases $(n=182)$, flaws in the health care services were identified as the cause of death: “...during his first hospital stay, my son caught pneumonia and a hospital infection, that were the causes of his death..." In the majority of such cases, mothers associated the flaws with performance by the attending health care professionals (110 reports $-27.8 \%$ of the cases), “...after [the doctor] gave him that shot, he got worse and died. The doctor kept the prescription for the injection...".

\section{Comments and conclusions}

Analysis of the reports identified the 11 most frequent signs, and particularly the ones valued by the mother to characterize the onset or evolution of her child's illness. Each of these signs was described according to some specific characteristics indicating onset, worsening, or improvement of the illness. The analysis demonstrated a logical chain from the identification of alterations in the child's condition, the evaluation and interpretation of these alterations, and the search for treatment. Identification of a given sign appears to influence both the moment of the search and the type of service visit-

\begin{tabular}{|c|c|c|c|c|}
\hline \multicolumn{5}{|c|}{$\begin{array}{l}\text { Distribution of results obtained from visits to hospital or health post, as reported } \\
\text { by mothers. Greater Metropolitan Belo Horizonte, Minas Gerais State, Brazil, } \\
\text { 1991-1992. }\end{array}$} \\
\hline \multirow[t]{2}{*}{ Result of treatment } & \multicolumn{2}{|c|}{ Hospital } & \multicolumn{2}{|c|}{ Health Post } \\
\hline & $\mathrm{n}$ & $\%$ & $n$ & $\%$ \\
\hline Improved & 121 & 13.9 & 21 & 12.0 \\
\hline Worsened & 68 & 7.8 & 17 & 9.7 \\
\hline No change & 86 & 9.9 & 38 & 21.7 \\
\hline Not reported by mother & 125 & 14.4 & 37 & 21.1 \\
\hline Referred to another health service & 119 & 13.7 & 44 & 25.1 \\
\hline Did not receive treatment & 21 & 2.4 & 8 & 4.5 \\
\hline Died while in care & 238 & 27.5 & 5 & 2.8 \\
\hline Dead on arrival & 87 & 10.0 & 5 & 2.8 \\
\hline Total number of visits & 865 & 100.0 & 175 & 100.0 \\
\hline
\end{tabular}

ed. It was clear that mothers turned to the health post principally in cases where the predominant signs were associated with onset of the illness, characterizing a non-serious problem. On the other hand, when mothers identified alterations they associated with worsening of the illness, they took their children directly to the hospital. Extensive use of hospitals can be explained by the idea that this type of health care facility guarantees the provision of more complex treatment. Meanwhile, mothers associate the health post with a more limited caseresolving capacity.

Maternal assessment of quality of care received at the health care services shows a high degree of dissatisfaction. Some $43.0 \%$ of mothers complained about the quality of the health care services, mainly the structure and organization of the quality of care received. Using the percentage of return visits to the same service as an indicator of satisfaction, an extremely high rate of dissatisfaction characterizes the mothers' relationship to both the hospital and the health post (Gattinara et al., 1995). According to Horovitz (1991, apud Gattinara et al., 1995), a satisfied person tells three others about the reason for his/her satisfaction, while a dissatisfied person tells eleven others. The reputation of health care services, as well as the way some mothers feel in seeking treatment at these facilities, can be better understood from this perspective.

Mothers gave a negative assessment to the results of $17.7 \%$ of visits to the hospital and $31.4 \%$ to the health post. This negative assessment was mainly associated with the medication prescribed by the attending physician. Some moth- 
ers claimed that the medication had no effect or that they were unable to determine how it was supposed to be given to the child. Mistreatment, negligence, and incapacity on the part of the health care professional encompass the other problems identified by mothers.

The negative assessment by a large proportion of mothers in relation to both the quality and results of care, the low rate of return visits to the same facility consulted previously, and the numerous complaints about the attending health care personnel demonstrate the very real problems that must be dealt with, and that health care professionals need to change their approach, even to obtain success in treatment. An example is the mismatch between the mothers' perception that the appearance of cough requires turning to professional help and the underrating of this alteration by health care professionals themselves. Such problems refer to difficulties in communications between physicians and patients (or their families), the gap between the explanatory models (Kleinman, 1978) employed by physicians, and various universes of beliefs and values that transform alterations in the child's state of health into signs of greater or lesser severity and determine specific decisions and actions vis-à-vis these signs (Corin et al., 1992; Garro \& Young, 1983). Note here that the perception of what is relevant and problematic, what causes or prevents a problem, and the type of action that this same problem requires is determined (for patients and their families) by symbolic networks that link biomedical and cultural concepts and determine characteristic ways of thinking and acting towards a health problem (Uchôa \& Vidal, 1994).

Thus, in order to identify and diminish the risks to which individuals in a community are exposed and to conduct appropriate and effective actions in public health, it is crucial to have prior knowledge of the characteristic and predominant ways of thinking and acting in this target group.

\section{Acknowledgments}

The authors wish to thank all the mothers who shared parts of their stories with this study. The authors also gratefully acknowledge the financial support of PanAmerican Health Organization, Fundação de Amparo à Pesquisa do Estado de Minas Gerais, and Coordenação de Aperfeiçoamento de Pessoal de Nível Superior. 


\section{References}

ATKINSON, S. J., 1993. Anthropology in research on the quality of health services. Cadernos de Saúde Pública, 9:283-299.

CORIN, E.; BIBEAU, G. \& UCHÔA, E., 1993. Eléments d'une sémiologie anthropologique des troubles psychiques chez les Bambara, Soninké et Bwa du Mali. Anthropologie et Sociétés, 17:125-156.

CORIN, E.; UCHÔA, E.; BIBEAU, G. \& KOUMARE, B., 1992. Articulation et variations des systèmes de signes, de sens et d'actions. Psychopathologie Africaine, 24:183-204.

DEMICHELI, W. A. \& UCHÔA, E., 1997. QUALITTAT Um Programa de Análise Qualitativa para Microcomputador. CD-ROM. Belo Horizonte: Centro de Pesquisas René Rachou, Fundação Oswaldo Cruz.

EISENBERG, L., 1981. The physician as interpreter: Ascribing meaning to the illness experience. Comprehensive Psychiatry, 22:239-249.

FRANÇA, E., 1995. Estudo dos Determinantes da Mortalidade Infantil por Diarréia, Pneumonia e Desnutrição na Região Metropolitana de Belo Horizonte em 1991-1992. Tese de Doutorado, Belo Horizonte: Faculdade de Medicina, Universidade Federal de Minas Gerais.

GARRO, L. Y. \& YOUNG, J. C., 1983. Atención de salud en minorias étnicas rurales. Algunas observaciones antropológicas. Boletín de la Oficina Sanitaria Panamericana, 95:333-344.

GATTINARA, B. C.; IBACACHE, J.; PUENTE, C. T.; GIACONI, J. \& CAPRARA, A., 1995. Percepción de la comunidad acerca de la calidad de los servicios de salud públicos en los distritos Norte e Ichilo, Bolivia. Cadernos de Saúde Pública, 11:425-438.

IBGE (Fundação Instituto Brasileiro de Geografia e Estatística), 1993. Sinopse Preliminar do Censo Demográfico. Rio de Janeiro: IBGE.
KLEINMAN, A., 1978. Concepts and a model for the comparison of medical systems as cultural systems. Social Science and Medicine, 12:85-93.

KLEINMAN, A., 1980. Patients and Healers in the Context of Cultures. An Exploration of Borderland between Anthropology and Psychiatry. Berkeley/Los Angeles: University of California Press.

LANSKY, S. \& MENDONÇA, E. F., 1996. Vigilância de óbitos evitáveis: A experiência de um Centro de Saúde de Belo Horizonte. Revista Médica de Minas Gerais, 6:64-68.

MULL, D. S.; MULL, D. J.; MALIK KUNDI, M. Z. \& ANJUM, M., 1994. Mother perceptions of severe pneumonia in their own children: Controlled study in Pakistan. Social Science and Medicine, 38: 973-987.

NATIONS, M. K. \& REBHUN, L. A., 1988. Angels with wet wings won't fly: Maternal sentiment in Brazil and the image of neglect. Culture, Medicine and Psychiatry, 12:141-200.

SCHEPER-HUGHES, N., 1984. Infant mortality and infant care: Cultural and economic constraints on nurturing in northeast Brazil. Social Science and Medicine, 19:535-546.

UCHÔA, E.; CORIN, E.; KOUMARÉ, B. \& BIBEAU, G., 1993. Representations culturelles et desqualification sociale: L'epilepsie dans trois groupes ethniques au Mali. Psychpathologie Africaine, 26:33-54.

UCHÔA, E. \& VIDAL, J. M., 1994. Antropologia médica: Elementos conceituais e metodológicos para uma abordagem da saúde e da doença. Cadernos de Saúde Pública, 10:497-504.

Submitted on 3 July 2001

Final version resubmitted on 24 October 2001

Approved on 17 January 2001 